\title{
COMMUNICATIONS
}

\section{ANTHROPOLOGICAL STUDIES ON THE NATURE OF CYCLOVERTICAL SQUINT*}

\author{
BY
}

\author{
A. URRETS-ZAVALÍA, JR., J. SOLARES-ZAMORA, AND H. R. OLMOS \\ From the Ophthalmic Clinic, Universidad Nacional de Córdoba Medical School, Córdoba, \\ Argentina
}

THE fact that, in cases of strabismus with a vertical imbalance, slight facial malformations of a definite character are consistently found has previously been assessed and discussed by one of us (Urrets-Zavalía, 1954, 1955).

When, owing to an overaction of the inferior oblique, and regardless of whether a divergent or convergent deviation is present, elevation in adduction, divergence on looking up, and/or convergence on looking down exist - as described by Urrets-Zavalía (1948a) $\dagger$-a downward-slanting appearance of the palpebral fissures and an S-shaped contour of the lower lid margins are frequently seen, in association with some degree of hypoplasia of the malar bones which causes a more or less conspicuous flattening of the external and inferior orbital margins and of the upper part of the cheek.

On the other hand, in the somewhat rarer cases in which the opposite motor disturbances (depression in adduction, convergence on looking up, and/or divergence on looking down) are due to an underaction of the same muscle (Urrets-Zavalía, 1948b), a mongoloid obliquity of the lid axes and a certain narrowing of the palpebral openings usually prevail. The cheek bones are then well developed and the lower lid borders appear straight rather than curved.

It thus appeared that the aforementioned disturbances of the ocular muscles are in some way related to the accompanying disorders of the facial scaffolding, and that the cases of squint in which they occur are developmental in nature and result from errors affecting the growth of the first, pre-mandibular somite. This is why these defects, together with others due to a dysontogenetic process of the neighbouring structures, have been classified under the label of peristomodeal malformations (Urrets-Zavalía, 1956).

In order to ascertain whether this viewpoint was indeed justified and to collect some factual evidence upon which it could be substantiated or disproved, it was thought desirable to submit a large number of persons of clear-cut cranio-facial characteristics, as would be determined by a given racial background, to a careful screening for all possible oculomotor

* Received for publication August 25, 1960.

$\dagger$ Previous brief references to this had been made by Bielschowsky (1939), Anderson (1947), and Berke (1947). 
anomalies. Among the Caucasian races a malar hypoplasia and a downward obliquity of the lid axes are, though common enough, by no means the rule (high cheek bones often being the patrimony of persons of white northern European and of Slav stock), while in certain Mongolian races an exaggerated development of the cheek bones with an upward slanting appearance of the palpebral apertures is fairly constant; it was therefore considered that the latter, rather than the former, should be preferred, on the assumption that in such races underaction of the inferior oblique would exceed overaction of the same muscle if our hypothesis were true.

A first requisite of the population to be tested was that the upper facial structures, particularly the cheek bones, were highly developed, that the palpebral fissures possessed what has come to be known as a mongoloid obliquity, and that the eyes were narrow and almond-shaped. As these traits are regularly seen in marked form in only a few of the ethnic groups belonging generally to the yellow and the American Indian races, a careful selection on the basis of these special features was needed. The material chosen should, in addition, be homogeneous-in so far as homogeneity goes in the matter of any human assemblage classed as forming a separate racial unit-i.e. comparatively free from blood admixtures due to interbreeding with other, clearly distinct, races, in this case mainly with Negro and European immigration currents.

Moreover, as research work on strabismus and allied conditions is almost without exception conducted in children, it was felt that only persons below a definite age limit should be taken into account if the results were to be of value when compared with those elicited in other communities. Again, and for the same reason, since it may be supposed that the optomotor behaviour of young people is influenced by the educational efforts to which they are subjected, it is evident that either children of pre-school age or children attending school regularly should be considered.

With these thoughts in mind, a scrutiny was made of every racial group on whose facial peculiarities precise information could be gathered. It soon became apparent that some of the South-American aborigines, such as the Quechua and even more the Aymara Indians found in Bolivia, were ideally suited for the contemplated mass study, in that their cephalic conformation corresponded well to the above-mentioned specifications. As good elementary school facilities have now been made available to them, and attendance at the educational and welfare centres is compulsory, it turned out that the survey could be conducted in Indian children of much the same visual habits as those prevalent among the white races.

\section{Material and Method of Investigation}

As a result of this, and of the unfailing co-operation of the educational authorities and members of the medical profession, whose patience and endurance 
were at times, it is feared, very heavily taxed, Bolivia was chosen as the site of the intended research.

Of an estimated population of $3,700,000$, scattered over an area of $1,470,040$ sq. kilometres, only some 150,000 are pure white, mostly of Spanish origin, and 350,000 are mestizos, the remaining 3,200,000 being native American Indians. From the ethnic and the philological points of view, these may be regarded as belonging to three distinct groups (Fig. 1).

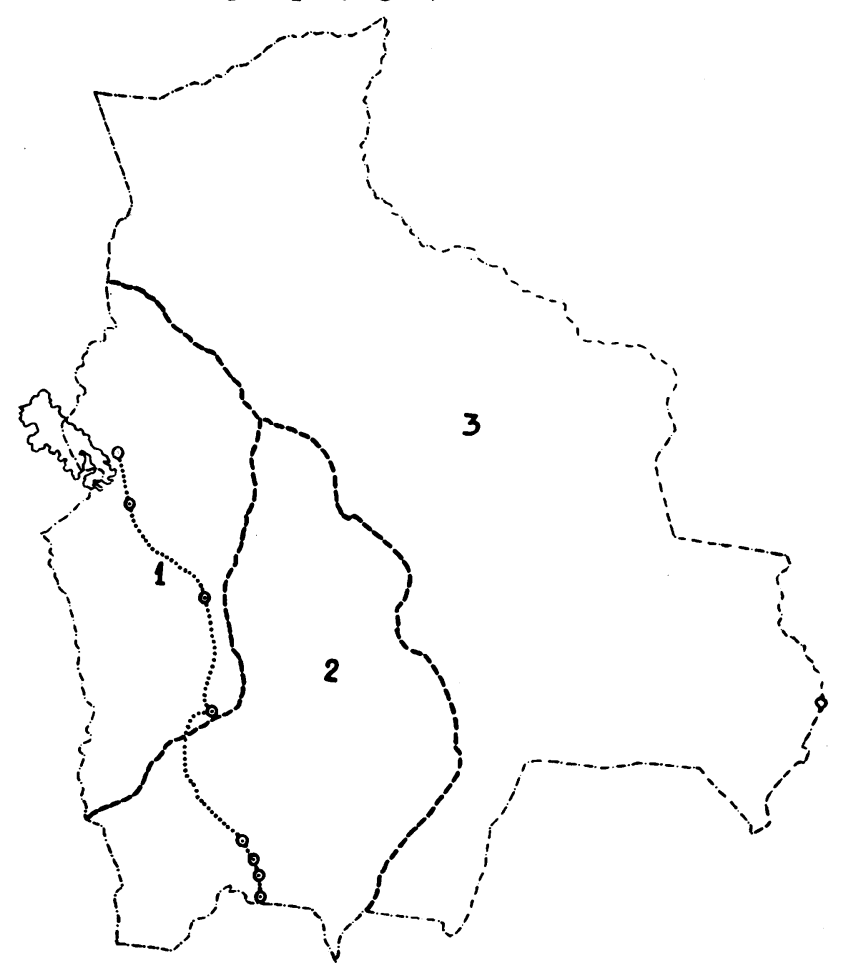

FIG. 1.-Approximate distribution of main ethnic groups in Bolivian territory. 1. Aymara, 2. Quechua, 3. Guarani.

The Guaranis, who are related to the meridional Tupian tribes and dwell in the northern and eastern tropical forests and swamps traversed by several large tributary streams of the Amazon river, such as the Beni, the Mamoré, and the Guaporé.

The Quechuas, who inhabit the oriental slopes of the Andes and the southern stretch of the Altiplano (the high meseta which occupies the western part of Bolivia); their ancestors constituted the dominant element in the Inca Empire.

The Aymaras, who live in limited numbers in the northern two-thirds of the Altiplano, in the west-central section of the country; their forefathers developed an advanced pre-Inca culture.

Although the Guarani and germane races exhibit a marked development of the massif facial (as may be seen in the excellent photographs illustrating the report of Belfort Mattos (1958) on some visual aspects of the Brazilian Indians), they are thinly disseminated over extensive and mostly unwholesome areas where little or no transportation exists and live in a most primitive manner; this made them less 
promising material than the Quechua and Aymara races which, besides being equally or even more suitable from the morphological point of view, are in permanent and relatively close contact with civilization.

A route was planned to include several towns and villages, some belonging to large mining developments, where the Indians are concentrated in compact social units. Transportation by special rail and car service was secured through the assistance of several public and private organizations. Tupiza, Telamayu, Atocha, Quechisla, Catavi, and Warisata were thus visited in succession over a period of about 5 weeks (Fig. 2).

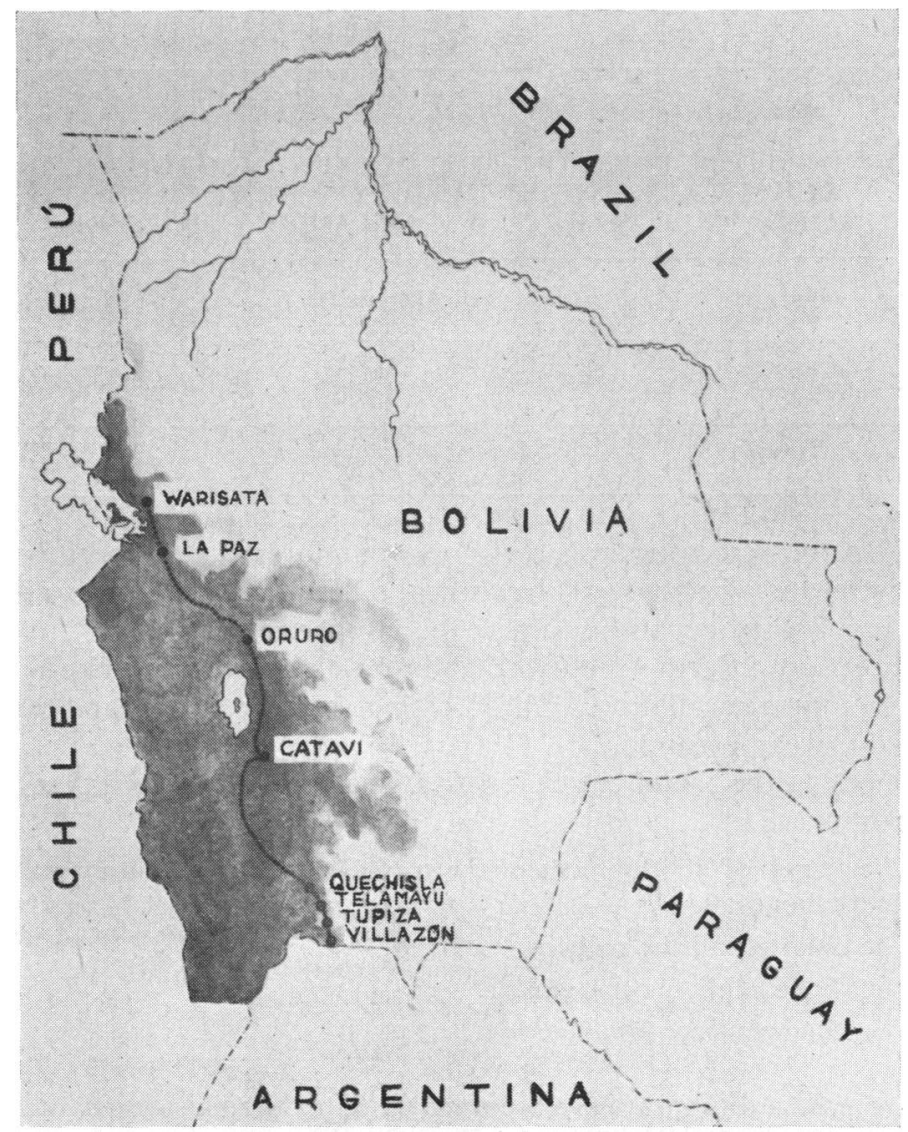

FIG. 2.-Map of Bolivia, showing route and places visited.

The altitude, varying from 3,005 to $4,400 \mathrm{~m}$. (Tables I and II, opposite), was often a cause of acute discomfort, chiefly in the form of severe analgesic-resistant headaches, and of dyspnoea, probably due to hypoxia.

Only children who regularly attended an elementary school, or were under the 6-year age-limit were examined, in a total number of 4,615. A thorough investigation of all possible latent or manifest deviations in the primary position and eight cardinal directions of gaze, both at $5 \mathrm{~m}$. and at $33 \mathrm{~cm}$., was carried out. Whenever 
TABLE I

GEOGRAPHICAL DISTRIBUTION OF CHILDREN OF GROUP I, IN WHICH ALL CASES OF MANIFEST OR LATENT OCULOMOTOR ANOMALIES WERE CONSIDERED

\begin{tabular}{c|c|c}
\hline Place & Altitude (m.) & Number of Cases \\
\hline Tupiza & 3,005 & 1,324 \\
Telamayu & 3,706 \\
Atocha & $3,658\}$ & 549 \\
Quechisla & 3,460 & 216 \\
\hline Total & & 2,089 \\
\hline
\end{tabular}

TABLE II

GEOGRAPHICAL DISTRIBUTION OF CHILDREN OF GROUP II, IN WHICH ONLY CASES WITH A MANIFEST DEVIATION IN AT LEAST ONE OF THE CARDINAL POSITIONS OF GAZE WERE CONSIDERED

\begin{tabular}{c|c|c}
\hline Place & Altitude (m.) & Number of Cases \\
\hline Catavi & 3,734 & 2,137 \\
Warisata & 4,400 & 389 \\
\hline Total & & 2,526 \\
\hline
\end{tabular}

possible, the prism-screen test was used; only in infants was the position of the eyes estimated by means of a study of the corneal reflexes. A careful search was made for such reactions to occlusion (innervational phenomena) as latent nystagmus, cyclodeviations on covering the fixing and non-fixing eye, and alternating hyperphoria. The influence-if any-of head-tilting was also noted, and the near point of convergence was measured.

With respect to the facial characteristics, special notice was taken of the four following points:

(1) The degree of development of the medial and the lateral aspect of the zygomatic bones;

(2) The obliquity of the palpebral fissures;

(3) The shape of the lid margins;

(4) The interpupillary distance.

In order to assess quantitatively the magnitude of the existing slant, a ruler was held flat and horizontally against the patient's forehead in such a way that the projection of its lower edge coincided with the highest of the four canthi; the apparent distance of the other canthi from the lower edge of the ruler was then reckoned in millimetres. Thus, for example, $0 /-3 /-4 / 0$ meant that the right inner commissure was $3 \mathrm{~mm}$. below, and the left internal commissure $4 \mathrm{~mm}$. below, a line passing through both external lid angles. As parallax errors would strongly influence such rough estimates of palpebral obliquity, the observer's eye had to be kept level with the eyes of the subject, and the head of the latter had to be maintained in an erect position. 
Anthropometric measurements of the sort used by Jöhr (1953) and by Grab (1956) in the study of cases of hypertelorism and of blepharophimosis were considered of no immediate practical consequence in the present investigation.

The media and fundi were examined, and the refraction determined, under one per cent. cyclopentolate hydrochloride (Cyclogyl) cycloplegia in all patients suffering from a motor disturbance, and the visual acuity measured with full correction.

Of all the collected data, however, only those considered to have a direct bearing upon the problem in hand are presented in this paper.*

In order to be in a better position to appreciate the racial background of the affected cases, the national origin and place of birth of the four grandparents of each were traced. As migrations are relatively uncommon among such sedentary peoples as the Quechua and Aymara, this usually involved no special difficulties.

In a first group of 2,089 children examined in Tupiza, Telamayu, Atocha, and Quechisla, and who belonged predominantly to the Quechua family, all cases with a manifest or latent deviation of the visual axes, including one instance of pure alternating hyperphoria, were listed (Table I). In a second group of 2,526 children examined in Catavi, where a strong Aymara influence was already apparent, and in Warisata, where the population was exclusively of Aymara extraction, only those cases showing a manifest deviation in at least one of the cardinal positions of gaze were taken into account (Table II).

\section{Results}

In confirmation of what had already been observed by A. Solares (1957), the comparative rarity of oculomotor disturbances in the material investigated became evident from the start (Table III).

TABLE III

INCIDENCE OF OCULOMOTOR ANOMALIES IN GROUPS I AND II

\begin{tabular}{|c|c|c|c|c|c|c|c|c|c|}
\hline \multirow{4}{*}{ Group } & \multirow{4}{*}{$\begin{array}{c}\text { Total } \\
\text { Number } \\
\text { of } \\
\text { Cases }\end{array}$} & \multirow{3}{*}{\multicolumn{2}{|c|}{$\begin{array}{c}\text { Total } \\
\text { Affected }\end{array}$}} & \multicolumn{6}{|c|}{ Deviation } \\
\hline & & & & \multirow{2}{*}{\multicolumn{2}{|c|}{ Latent }} & \multicolumn{4}{|c|}{ Manifest } \\
\hline & & & & & & \multicolumn{2}{|c|}{$\begin{array}{l}\text { In at Least One } \\
\text { Position of Gaze }\end{array}$} & \multicolumn{2}{|c|}{$\begin{array}{l}\text { In the Primary } \\
\text { Position }\end{array}$} \\
\hline & & No. & Per cent. & No. & Per cent. & No. & Per cent. & No. & Per cent. \\
\hline I & 2,089 & 55 & 2.63 & 6 & 0.28 & 29 & 1.39 & 20 & 0.96 \\
\hline II & 2,526 & 7 & 0.28 & - & - & 1 & 0.04 & 6 & 0.24 \\
\hline
\end{tabular}

In Group I, comprising 2,089 children, 55 (2.63 per cent.) exhibited a muscular imbalance of some kind; of these, only 49 (2.35 per cent.) showed a manifest deviation in at least one of the main positions of gaze, the deviation in the remaining six being latent. If only cases of manifest, permanent or intermittent deviation in the primary position are considered, however,

\footnotetext{
* The remainder, partly or in full, will be sent on request to other writers engaged in investigations on similar subjects.
} 
the number of affected cases falls to twenty ( 0.96 per cent.). The number is still further reduced if the three white strabismic children who happened to be included in this group are subtracted from the total number and from the number of manifest deviations in the primary position, which thus becomes seventeen $(0.81$ per cent.).

In Group II, comprising 2,526 children, only seven ( 0.28 per cent.) showed some oculomotor disturbance, and only six ( $0 \cdot 24$ per cent.) had a manifest deviation in the primary position. The seventh had a unilateral ptosis and showed exotropia on looking up.

GrouP I.-These patients showed a manifest or latent deviation. In the following classification they are arranged in an esotropia-orthotropiaexotropia* gradation, according to the severity and the complexity of the deviation $\uparrow$ :

(1) Two cases ( $\mathrm{Te} 1$ and Te 3) had a constant esotropia in the eyes-front position, which remained unaffected on looking up and down. In one, weakness of the left inferior oblique was present, and in the other no imbalance of the verticallyacting muscles was observed. Both showed markedly mongoloid facies.

(2) One case (Te 8) showed a permanent esotropia in the primary position which diminished on looking down and increased on looking up. No individual muscular disturbances seemed to be present, but the child was only 2 years old and cooperation was poor. The facies was markedly mongoloid.

(3) Two cases (Tu 7 and Tu 21) presented a permanent esotropia in straightforward gaze; the deviation diminished markedly on looking down and became more conspicuous on looking up. One case showed a unilateral, and the other a bilateral, underaction of the inferior oblique muscle. Both showed a markedly mongoloid facial development.

(4) One case (Qu 2) exhibited only a slight permanent left hypotropia in the primary position, to which a moderate exotropia was added on looking down and a moderate esotropia on looking up. An underaction of the left inferior oblique and an overaction of the left superior oblique were clearly seen on dextroversion. A mild degree of alternating hyperphoria was likewise present. The facies was markedly mongoloid.

(5) Four cases (Tu 3, Tu 15, Tu 36, and Tu 41) were nearly orthophoric in the primary position, but displayed a latent divergent deviation on looking up, and a latent convergent deviation on looking down. One had no discernible individual muscular disorders, two showed a bilateral overaction of the inferior oblique, and one showed an overaction of the right inferior oblique, together with a pronounced

\footnotetext{
* The term orthotropia is used to designate the condition wherein the eyes are straight when uncovered, irrespective of whether or not a latent deviation may be brought about by any of the dissociating devices.

$\dagger$ For the sake of expediency all non-functional disturbances of the vertical muscles (as opposed to clearly innervational disturbances, which vary not with the position of gaze but with occlusion of the non-fixing eye or with placing tional disturbances, which vary not with the position of gaze but with occlusion of the non-fixing eye or with placing
a dark glass in front of the fixing eye) will be described wherever possible in terms of overaction or underaction of the a dark glass in front of the fixing eye) will be described wherever possible in terms of overaction or underaction of the
inferior oblique muscle. It must be understood, however, that this muscle may not always be primarily at fault: an inferior oblique muscle. It must be understood, however, that this muscle may not always be primarily at fault: an
overaction might be secondary to a weakness of the homolateral superior oblique or the contralateral superior rectus, and an underaction might be secondary (through inhibitional paresis) to a weakness of the contralateral antagonist, i.e. the inferior rectus of the opposite eye (Urrets-Zavalia, 1948c, 1950, 1952).
} 
weakness of the homolateral superior oblique. In this last case, by tilting the head upon a sagittal axis towards the left shoulder, the vertical imbalance almost disappeared; conversely, on tilting the head towards the right shoulder, the right eye assumed a still higher position. In all four, the facies was mongoloid.

(6) 27 cases were orthotropic in the primary position and on looking down, but showed an insurmountable exotropia on looking up (Tu 8, Tu 9, Tu 11, Tu 12, Tu 13, Tu 14, Tu 16, Tu 18, Tu 19, Tu 20, Tu 22, Tu 24, Tu 26, Tu 30, Tu 32, Tu 34, Tu 35, Tu 38, Tu 39, Tu 40, Te 2, Te 4, Te 6, Te 7, Te 9, Te 10 and Te 11). In most of these, a moderate to marked exophoria was present in the primary position. In only five were there no visible signs of vertical imbalance (one had, however, a right palpebral ptosis); twenty showed a bilateral overaction of the inferior oblique, and two a unilateral overaction of the inferior oblique, which was associated in one with marked weakness of the homolateral superior oblique and with a clear effect of head-tilting (Bielschowsky's sign). All these patients had well-defined mongoloid traits.

(7) In three cases ( $\mathrm{Tu} 10, \mathrm{Tu} 29, \mathrm{Tu} 31$ ), an intermittent exotropia was noticed in the primary position; the exodeviation became permanent and more marked in elevation, whereas in depression the eyes were orthophoric in one case, and permanently orthotropic-though still slightly exophoric-in the other two. In all these cases a bilateral overaction of the inferior oblique was present. All three had mongoloid facies.

(8) In one case $(\mathrm{Qu} 3)$, there was a permanent right exotropia and hypotropia in the primary position and on looking up; on looking down the deviation, though still present, became less marked. The left inferior oblique was found to be moderately overactive. No torticollis was present; yet on tilting the head towards the right shoulder the vertical deviation increased, whereas it first decreased and then disappeared as the head was tilted towards the left shoulder. The facies was mongoloid.

(9) One case $(\mathrm{Qu} 1)$ had a permanent alternating exotropia in the primary position, which did not vary on looking down but increased markedly on looking up. A conspicuous though clearly asymmetrical overaction of both inferior oblique muscles was present. A coarse, irregular, pendular horizontal nystagmus existed, which became more pronounced on covering the right eye, but remained unaltered on covering the left eye and also on conjugate deviation towards one side or the other. There was severe bilateral fundus damage due to old chorio-retinitis. The visual acuity with glasses was only $0 \cdot 2$ in each eye. The facies was mongoloid.

(10) In three patients ( $\mathrm{Tu} 1, \mathrm{Tu} 2, \mathrm{Tu} 23$ ), a permanent exotropia was seen, which increased on looking up and diminished on looking down. Two had bilateral overaction of the inferior oblique, one of them with alternating hyperphoria; in the third case, no individual muscular disorders were detected. All three had mongoloid facies.

(11) In two pure white patients (Tu 5 and Tu 17), the children of European immigrants, a permanent esotropia was found in the primary position. In one, the defect decreased on looking up and increased on looking down, and in the other the deviation did not vary on looking down but decreased on looking up. Both had a unilateral overaction of the inferior oblique muscle. 
A further patient ( $\mathrm{Tu} 27$ ), who could be described as 75 per cent. white (quadroon) and who showed no obliquity of the palpebral fissures, was orthotropic in the primary position and on looking up; on looking down, however, he showed a permanent alternating exotropia. There was an underaction of the left inferior oblique and a slight positive (right/left) vertical phoria, which disappeared on tilting the head towards the right side and became more pronounced on tilting the head towards the left.

As will be seen presently, the 48 cases listed so far-of which the first 45 were of pure Indian blood-all fall into clear-cut categories. To them must be appended an additional 7, which seem to represent either exceptions to the general trend or instances of basically different entities:

(12) In one case ( $\mathrm{Tu} 6$ ), a permanent alternating esotropia existed in the primary position, which did not vary on looking up but disappeared on looking down. A slight overaction of the right inferior oblique was present. The child was of mixed parentage and could be considered 50 per cent. white, but the facies was mongoloid.

In a second case ( $\mathrm{Te}$ 5), a left esotropia and hypertropia were present in the primary position. No change was seen on looking up, but on looking down there was a marked exaggeration of the esotropia. There was an overaction of the left inferior oblique, with an apparent weakness of the homolateral superior oblique. The facies was mongoloid, although this patient also was a mestizo (50 per cent. white).

In a third case ( $\mathrm{Tu} 37)$, there was a permanent right esotropia in the primary position which decreased on looking up and increased on looking down. There was bilateral overaction of the inferior oblique. The child also was a mestizo (50 per cent. white), but features were only slightly mongoloid.

A fourth case ( $\mathrm{Tu} 28$ ) showed an intermittent alternating exotropia in the primary position, which decreased on looking down and increased and became constant in looking up. There was overaction of the right inferior oblique. The patient, who was the offspring of pure-white parents, suffered from a mild form of Crouzon's cranio-facial dysostosis; her malar development was poor and her palpebral fissures slanted downwards, the lower lid margins showing an S-shaped contour.

A fifth case (Tu 25) was orthotropic in the primary position and on looking down. Looking up caused permanent exotropia. No individual muscular weakness was found. The child was a mestizo (50 per cent. white). The facies could not be said to be of any definite type, and there was no obliquity of the palpebral fissures.

(13) In one case ( $\mathrm{Tu} 4)$, in which the eyes were constantly orthotropic, even in extreme vertical excursions, and no individual muscular disturbance existed, an alternating hyperphoria, though no latent nystagmus, appeared with the screen test. The patient was of pure Indian blood with mongoloid facies.

In a second case ( $\mathrm{Tu} 33$ ), a moderate right esotropia and hypertropia existed in the primary position; in elevation and in depression the horizontal deviation diminished markedly. A slight overaction of the right inferior oblique, and an even slighter underaction of the left inferior oblique, were detected. The child was of pure Indian blood with mongoloid facies. 
GrouP II.-The seven patients in Group II all exhibited a manifest deviation in at least one of the main positions of gaze; the findings are arranged in sequence according to the same eso-ortho-exo progression:

(1) In one case ( $\mathrm{Ca} 4)$, a permanent alternating esotropia was present in the primary position, which did not vary on looking up but decreased markedly on looking down. The left inferior oblique was moderately weak. A bilateral, fine, jerky horizontal nystagmus was seen in the primary position, the fast phase being directed towards the side of the fixing eye. On uniocular occlusion, the rhythmic movement became more pronounced, as it did on maximum dextroor laevoversion. The child was of pure Indian blood with markedly mongoloid facies.

(2) One patient $(\mathrm{Ca} 6)$ had a permanent right esotropia in the primary position. This did not alter on looking up, but first decreased and finally gave way to an exotropia as the eyes moved downward. There was an underaction of both inferior obliques, more marked on the right side. Alternating occlusion resulted in elevation and extorsion of the covered eye, and in a slight intorsion of the fixing eye. No spontaneous torticollis was present; yet, when the head was tilted towards the right shoulder, the right eye was seen to assume a somewhat lower position, and on tilting the head towards the left shoulder, there was an upshoot of the right eye. The patient was of pure Indian blood with conspicuously mongoloid facies.

(3) In one patient (Wa 1), who suffered from a right palpebral ptosis, orthotropia $(10 \triangle$ exophoria) was present in the primary position and on looking down. On looking up, a pronounced constant exotropia appeared. The right inferior oblique was markedly overactive. The child was of pure Indian blood with mongoloid facies.

(4) In one case ( $\mathrm{Ca} 3$ ), an intermittent alternating exotropia existed in the primary position, which did not change appreciably on looking up but became less pronounced and appeared less frequently on looking down. The eyes remained at the same level in all directions of gaze.

In a further case ( $\mathrm{Ca} 2)$, there was a permanent right exotropia, which was unchanged on looking down but increased markedly on looking up. Again, no imbalance of the vertically acting muscles could be detected. Several deep-seated corneal opacities existed in the right eye which had eccentric fixation. Both $\mathrm{Ca} 2$ and $\mathrm{Ca} 3$ were of pure Indian blood with mongoloid facies.

(5) One case ( $\mathrm{Ca} 1)$ had an intermittent left exotropia in the primary position and on looking down; on looking up, the deviation increased markedly and became constant. A bilateral overaction of the inferior oblique muscle existed. The patient was pure Indian with mongoloid facies.

(6) One last case ( $\mathrm{Ca} \mathrm{5)} \mathrm{showed} \mathrm{a} \mathrm{slight} \mathrm{permanent} \mathrm{left} \mathrm{exotropia} \mathrm{in} \mathrm{the} \mathrm{primary}$ position, which diminished a little on looking up and increased greatly on looking down. There was a gross underaction of the right inferior oblique and a moderate underaction of the left inferior oblique, as well as alternating (occlusion) hyperphoria. Tilting the head towards the right shoulder caused an upshoot of the left eye to appear, but tilting the head towards the left shoulder had no visible 
effect upon the position of the eyes. Like all the other cases in Group II, this patient was of Indian parentage with mongoloid facies.

\section{Discussion}

As may be seen from the above presentation, most of the patients in whom a latent or manifest horizontal deviation of the visual axes was present exhibited some sort of imbalance of the vertically-acting muscles. As this consisted more often in a unilateral or bilateral overaction of the inferior oblique than in an apparent weakness of the same muscle, the results would seem at first glance to differ from those usually found in the Caucasian races only in that the number of the recorded exodeviations is inordinately large when compared with the number of the esodeviations.

When, however, the nature of the vertical imbalance encountered in each case and the divergent or convergent character of the eventually coexisting horizontal deviation (Subgroups 1-10 of Group I, and Subgroups 1-5 of Group II) are correlated, the following facts emerge to form a rather typical pattern (Fig. 3, opposite):

(i) In cases in which an esotropia or esophoria exists in the primary position, some degree of symmetrical or asymmetrical underaction of the inferior oblique prevails as the apparent cause for the depression in adduction, the relative convergence on looking up, and/or the relative divergence on looking down, which are usually also present.

(ii) In cases in which an exotropia (either intermittent or permanent) or exophoria is observed in the primary position, a symmetrical or asymmetrical hyperfunction of the same muscle ordinarily exists, as indicated by the associated phenomena of elevation in adduction, divergence on looking up, and/or convergence on looking down.

(iii) In cases in which the eyes are orthophoric, or very approximately so, in the primary position, but which show a latent or manifest deviation on looking up or down, the tendency seems to be for an overaction of the inferior oblique to predominate, with the attending phenomena of divergence on looking up and convergence on looking down.

On the other hand, in patients of white European stock, in whom malar hypoplasia causes the palpebral fissures to have a downward-slanting appearance, an overaction of the inferior oblique is generally associated with esotropia, and underaction with exotropia (Fig. 4, overleaf).

Thus, the statement of Crone (1954) that "esotropia is generally sursoadductory" and that "exotropia is almost always surso-abductory"* probably depended upon the fact that his own cases were of pure Caucasian stock and is valid only on that supposition. The same may be said of the assertion of Jampolsky (1957) that an increase in exodeviation on looking down, and a

\footnotetext{
* It would be better to speak of a deorsum-adductory rather than a sursum-abductory tropia, for the abducted eye, if not markedly amblyopic, is always used for fixation in extreme latero-version, so that the vertical movement affects the opposite adducted eye.
} 


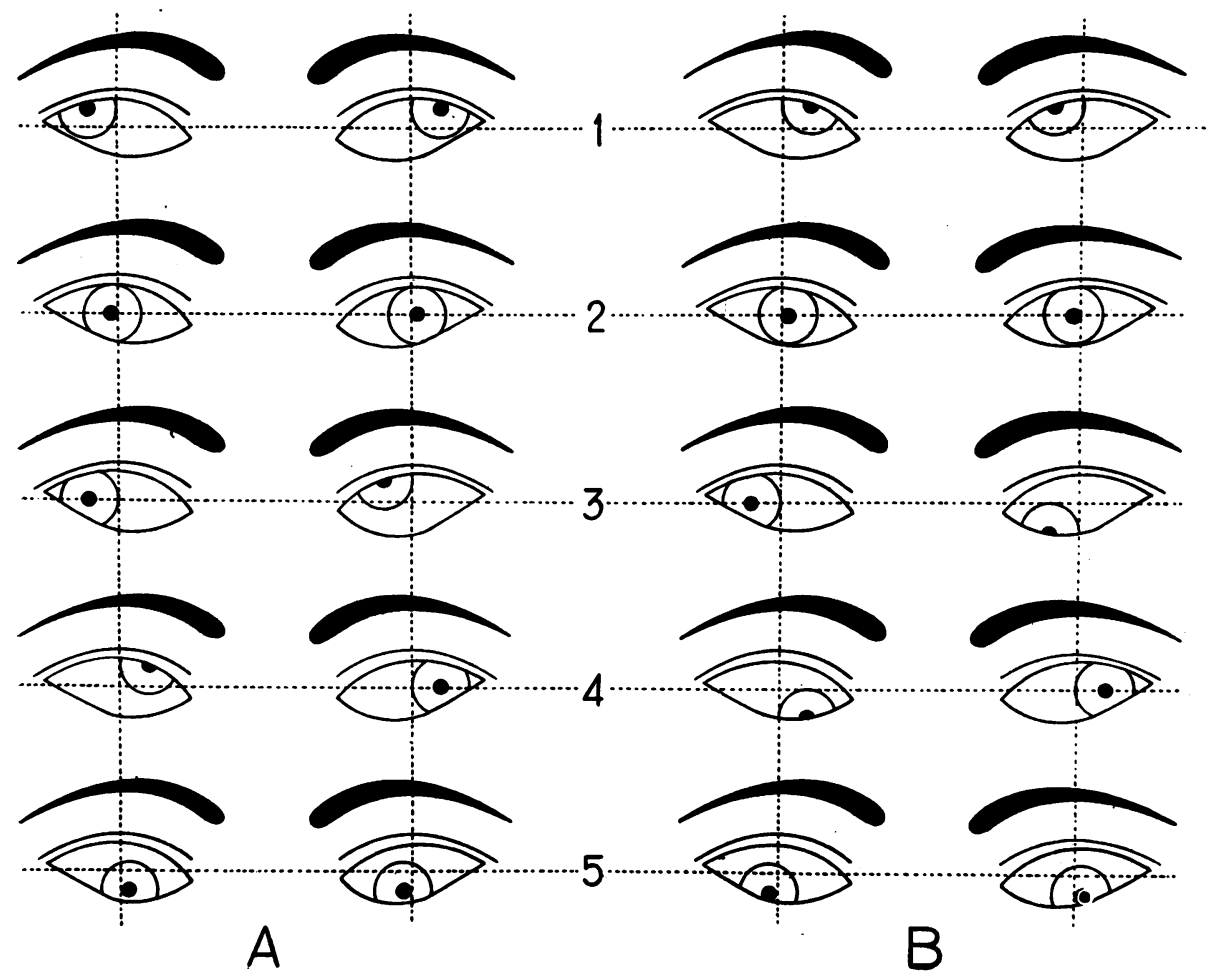

FIG. 3.-Schematic representation of state of affairs prevailing in strabismic patients with mongoloid facies where a vertical imbalance exists in association with a horizontal deviation. Note the mongoloid obliquity of the palpebral fissures and the straightened contour of the almondshaped lid margins; the more or less marked hyperplasia of the malar bones referred to in the text is not shown.

(A) If an exotropia is present in the primary position (2), further divergence on looking up (1), relative convergence on looking down $(5)$, and elevation in adduction $(3,4)$ are seen, as the result of an overaction of the inferior oblique muscles.

(B) When an esotropia is present in the primary position (2), convergence on looking up (1), divergence on looking down $(5)$, and depression in adduction $(3,4)$ are seen, apparently as the result of an underaction of the inferior oblique muscles.

bilateral overaction of the superior oblique, are most commonly observed in association with divergent strabismus, and also of the observation of Shekter (1955) that a relatively high incidence of weakness of the inferior recti is to be found in exotropia.

In confirmation of this, special mention must be made of the two strabismic children of European parentage included in Group I (Subgroup 11), who had antimongoloid facies and showed a unilateral overaction of the inferior oblique with an esotropia which decreased on looking up (in both) and increased on looking down (in one). A further case in the same subgroup, assessed as 75 per cent. white, whose face was of no definite type, showed a unilateral weakness of the inferior oblique with orthotropia in the primary position and exotropia on looking down. 


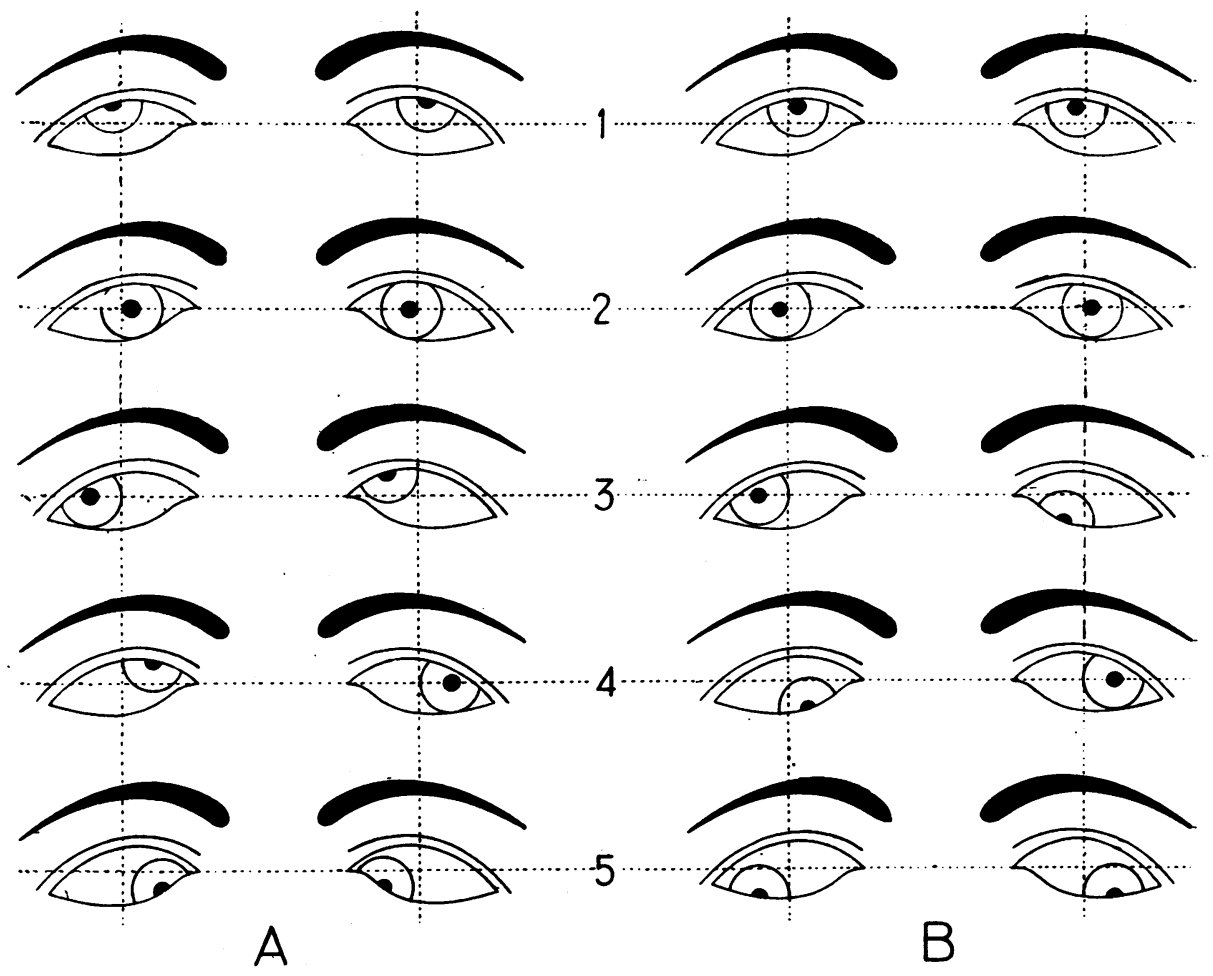

FIG. 4.-Schematic representation of state of affairs prevailing in strabismic patients with a Caucasian type of facial development where a vertical imbalance exists in association with a horizontal deviation.

Note the antimongoloid obliquity of the palpebral fissures and the S-shaped lower lid margins; the malar hypoplasia referred to in the text is not shown.

(A) When an esotropia is present in the primary position (2), divergence on looking up (1), convergence on looking down (5), and elevation in adduction $(3,4)$ are seen, apparently as the result of an overaction of the inferior oblique muscles.

(B) If an exotropia is present in the primary position (2), convergence on looking up (1), further divergence on looking down $(5)$, and depression in adduction $(3,4)$ are seen, as the result of an underaction of the inferior oblique muscles.

Two well-defined forms of the syndrome consisting of a horizontal strabismus combined with a vertical non-dissociated deviation may thus be established, according to:

(a) The vertical changes suffered by the reciprocal position of the eyes as they rotate on a vertical axis;

(b) The variations to which the horizontal relationship of both visual axes are subjected as they move around a transverse line;

(c) The different morphological features of the upper facial structures (Fig. 5, opposite). 


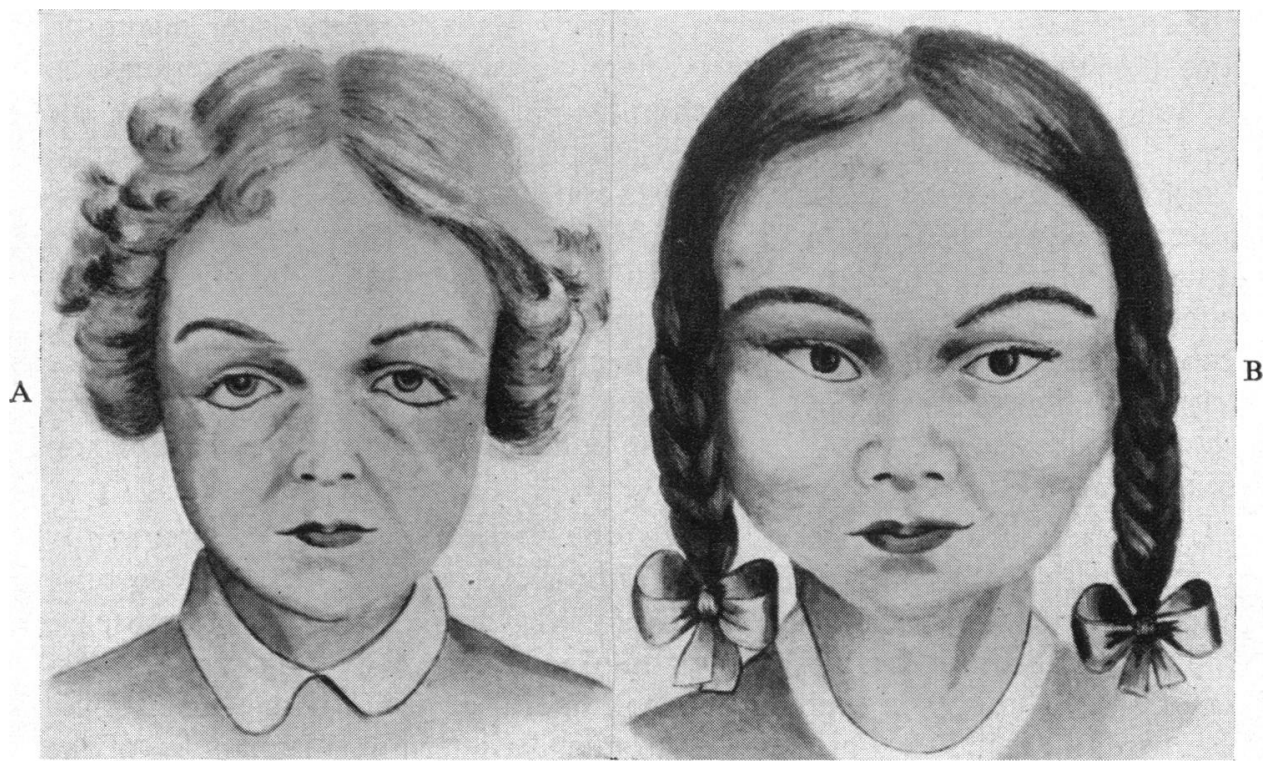

FIG. 5.-Composite drawings, made from a large number of photographs, showing the main features of (A) non-mongoloid and (B) mongoloid types of facies.

Note the markedly different degree of malar development, the obliquity of the palpebral fissures peculiar to each type, and the corresponding curve of the lid borders.

It must not be thought for one moment, however, that just because in cases with clear-cut mongoloid or antimongoloid features the disturbances encountered in the sphere of the vertically-acting muscles are nearly always of a distinct class, every case with similar motor defects will display such facial traits. In the light of what has been observed in squinting children with unmistakable mongoloid or antimongoloid features, one might suppose, however, that motor anomalies of a comparable kind, though more or less confined to the extra-ocular muscles, lie at the root of cases of $\mathrm{A}$ and $\mathrm{V}$ eso- and exotropia which show no visible obliquity of the palpebral fissures, where the facies is of no definite type.

From the large proportion of cases with an overactive inferior oblique found in the present series, one might be tempted to assume that the same vertical disturbance exists in both Caucasians and mongoloids, the difference being that in the former a trend to convergence, and in the latter a trend to divergence, of the visual axes results from some secondary factor, such as the refractive status or the disposition of the orbital axes. That this is not so is demonstrated by the fact that, in the less frequent cases showing underaction of the inferior oblique, the tendency for the horizontal deviation to be either convergent or divergent seems to work in the opposite direction, with a regular propensity towards esotropia in mongoloids and towards exotropia in Caucasians. 
It could also be argued that what really counts is the horizontal deviation, and that the vertical imbalance is merely a secondary phenomenon, the sursum- or deorsum-adductorial character of which is determined by the facial structure. This point is fully discussed elsewhere (Urrets-Zavalía, 1960); it need only be said here that several of the cases here reported (Subgroups 4, 5, and 6 of Group I, and Subgroup 3 of Group II) exhibited no deviation whatever in the primary position. This makes it difficult to attribute the existing vertical disturbance to a lateral tropia, since none existed. On the other hand, the dissociating influence of a primary vertical imbalance may cause the eventual appearance of a horizontal strabismus through forces which would otherwise have been kept in check by the normal compulsion to bifoveal fixation.

In at least a large number of cases, the vertical disturbances frequently coupled with horizontal strabismus (although variously attributed to pure innervational influences, to a secondary contracture of the oblique muscles, to an irregular insertion of the horizontal recti, or to the long-standing dissociation of the eyes brought about by a lateral deviation) must accordingly be regarded as due to a primary, anatomically-determined imbalance of the vertical muscles. Other, mainly innervational, anomalies may be added, as reactions to the dissociation occasioned by the primary defect, and the more so since the disruption of the binocular mechanism usually appears early in life in the more critical stages of development.

As shown by some of the cases described, all five constituents of both varieties of the syndrome described (over- or underdevelopment of the malar bones, mongoloid or antimongoloid obliquity of the palpebral fissures, a characteristic curve of the lid margins, relative convergence or divergence of the visual axes on looking up or down, and elevation or depression of the adducted eye) may be variously combined in incomplete forms.

Paradoxical or "against the rule" cases are also sometimes encountered. These were considered to be rather frequent (Urrets-Zavalía, 1956) before the interrelationship between the type of the existing cyclovertical disturbance and that of the facial structures was made clear by the present investigation, but now appear to be fewer in number. Thus, in one patient (Tu 6, Group I, Subgroup 12), the right inferior oblique was overactive although the facies was mongoloid, an esotropia existed, and the visual axes diverged on looking down.

In four other patients (Te 5, Tu 37, Tu 28, Group I, Subgroup 12; Ca 5, Group II, Subgroup 6), both the underaction or overaction of the affected muscles and the changes observed in the horizontal deviation on looking up and down were opposite to those which would have been expected according to the facies. Three of these children, however, were of mixed descent, despite the fact that the facial development was mongoloid, and the fourth, who was white, had a slight cranio-facial dysostosis (reminiscent of Crouzon's 
disease). In a fifth child (Tu 25, Group I, Subgroup 12), who was a mestizo, the facies was of no definite pattern.

In the two cases belonging to Group I, Subgroup 13, the oculomotor anomalies seemed to bear no demonstrable relationship to the fact that the children were of pure Indian blood with mongoloid facies.

The two main varieties of the syndrome just referred to represent only a basic norm, from which sporadic deviations are not rare; on no account, however, should the exceptions be allowed to overshadow the fact that this basic norm exists.

In this whole series there was not one instance of intermittent esotropia of a distinctly accommodative nature, where no vertical imbalance existed and where the deviation present in the primary position disappeared both on looking up and on looking down (a sign frequently seen in the cases of purely accommodative, periodic, convergent strabismus which can be corrected with glasses). Nor were there any instances of the truly concomitant, constant horizontal deviations so frequent in the Caucasian races, with no apparent vertical defect, in which looking up and down had no effect on the position of the eyes. This suggests that the absence of cases unquestionably attributable to an accommodative factor may be partly responsible for the low overall incidence of strabismus in the Indian races studied.

The absence of such cases may, in turn, be due to the fact that there are, in these races, lesser amounts of hyperopia than are usually found in the white races. Since the frequency with which abnormal degrees of hyperopia are associated in the white races with poor malar development cannot be merely due to chance, the existence of some connexion between these defects ought to be suspected. The reason for high hypermetropia is to be sought, it seems, in a failure of the mesoblastic layers encircling the optic cup to differentiate properly in response to the growth of the retina. When the defect has a more extended influence and involves the surrounding visceral mesoderm, malar anomalies, palpebral obliquity and even more remote somatic aberrations will appear (Urrets-Zavalía, 1956).

The evidence presented suggests that, in some children, regardless of whether a horizontal deviation appears as a secondary and often misleading feature, a peculiar imbalance of the vertically-acting muscles exists which manifests itself differently in the mongoloid and non-mongoloid types of facies. When the visual axes happen to remain parallel in the primary position, a unilateral or bilateral overaction of the inferior oblique prevails in both mongoloids and antimongoloids (though less consistently in the former, in whom an underaction of the inferior oblique is occasionally encountered) as the apparent cause for the accidentally observed elevation in adduction, divergence on looking up, and/or convergence on looking down. In patients with an associated convergent deviation in the primary position, the vertical disturbance varies in accordance with the skeletal 
pattern: underaction of the inferior oblique (or overaction of the superior oblique) will be found in the mongoloid, and an overaction of the inferior oblique (or underaction of the superior oblique) in the antimongoloid type of facial development. Conversely, in cases with an associated divergent strabismus, an overaction of the inferior oblique is seen in the former type of facies, and an underaction of the inferior oblique in the latter type.

It even appears that, in one and the same case, a hyper- or hypoactivity of a given muscle may become manifest as (spontaneously, in the course of time, through surgical interference with the horizontal muscles, or through other therapeutic measures) the visual axes shift from an eso- to an exotropic position, whereby they have to pass through a neutral point where no vertical disorder exists. As this neutral point is approached, the vertical anomaly observed in either the convergent or the divergent position will become less and less conspicuous and will finally disappear, only to reappear and increase again, although in the opposite sense, once that point has been passed (Fig. 6, opposite).

In the mongoloid type of facies, this transitional point seems to lie a little nasal to a sagittal plane passing through the centre of rotation of the eyeball, while in the non-mongoloid type, it lies a little temporal to this plane.

This would necessarily mean that, although the existence of the vertical anomaly is independent of the existence of a horizontal deviation, the presence and degree of the latter may influence the apparent severity of the former. In the light of the present findings, the explanation previously advanced (Urrets-Zavalía, 1956) of why the importance of the vertical defect alters with the changes in the degree of the horizontal deviation, appears to be considerably strengthened.

The precise nature of this imbalance of the obliques and of the vertical recti is not yet known. Although the clinical picture apparently warrants the conclusion that a weakness of certain vertically-acting muscles develops in certain circumstances, and that the character of this weakness depends upon the type of facial structure, there seems to be no valid reason to think that this weakness is due to a paralysis in the proper sense of the word.

\section{Summary}

Amongst a total 4,615 Quechua and Aymara Indian children in whom malar hyperplasia was the cause of an upward, or mongoloid, slant of the palpebral fissures, only 62 were found to suffer from an oculomotor disturbance. In most of these, some imbalance of the vertically-acting muscles was present, in addition to a latent or manifest horizontal deviation. When the nature of the vertical imbalance was correlated with the divergent or 


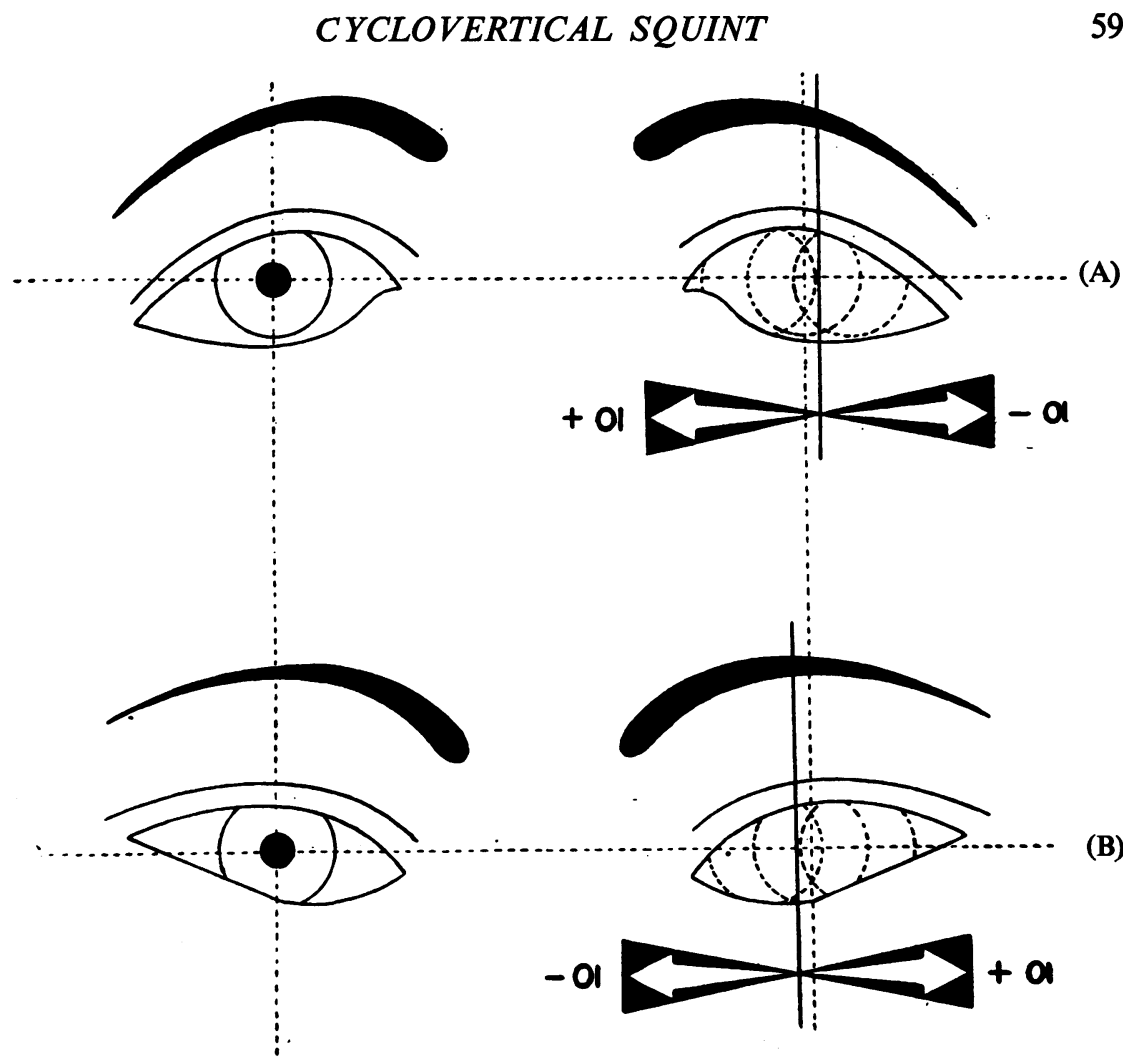

Fig. 6.-Diagrammatic representation of the prevailing vertical anomalies (described in terms of overaction or underaction of the inferior oblique muscle) seen in (A) antimongoloid and (B) mongoloid facies, according to the eventually convergent, parallel, or divergent position of the visual axes.

The dotted vertical lines stand for the sagittal plane passing through the hypothetical centre of rotation of the eyeballs.

The solid vertical line shows the approximate situation of the neutral or transitional point lying between the positions in which an overaction or an underaction of the inferior oblique is seen.

The area between the two lines corresponds to the narrow area of variability due to occasional slight changes in the position of the neutral point.

convergent character of the horizontal deviation, the following typical pattern was observed:

(i) Where an esotropia or esophoria existed in the primary position, some degree of symmetrical or asymmetrical underaction of the inferior oblique prevailed as the apparent cause of the depression in adduction, the relative convergence on looking up, and/or the relative divergence on looking down.

(ii) Where an exotropia (either intermittent or permanent) or an exophoria existed in the primary position, a symmetrical or asymmetrical overaction of the inferior oblique was usually associated with elevation in adduction, divergence on looking up, and/or convergence on looking down.

(iii) Where the eyes were orthophoric, or very nearly so, in the primary position, but showed a latent or manifest deviation on looking up or down, there was a 
tendency towards overaction of the inferior oblique, associated with divergence on looking up and convergence on looking down.

In the white races, on the other hand, where malar hypoplasia may cause the palpebral fissures to have a downward slanting, or antimongoloid, appearance, an overaction of the inferior oblique is usually associated with esotropia, and an underaction of the inferior oblique with exotropia.

The evidence presented seems to warrant the conclusion that, in some children, irrespective of whether a horizontal deviation appears as a secondary and often misleading feature or not, there is an abnormality of the vertically-acting muscles which manifests itself differently in the mongoloid and the non-mongoloid types of facies; and that, in at least a substantial number of cases, the vertical anomaly is due to a primary, anatomical imbalance of the vertically-acting muscles.

If we managed to stand up to the stress of our appointed programme, it was only thanks to the following persons, and to the institutions they represent, who helped us in planning our journey and carrying it out: Dr. Aniceto Solares (Professor of Ophthalmology, Universidad de Chuquisaca), Dr. José de la Vía (Chief Medical Officer, Hospital Telamayu), Dr. Rafael Torricos and Mr. Enrique Rozo (Chief Medical Officer and Superintendent of the Ferrocarril Villazón Atocha), Mr. Arturo Saunero (General Manager, Empresa Minera de Quechisla), Dr. Juan Peñarrieta (Chief Medical Officer, Empresa Minera de Catavi), Dr. Néstor Orihuela (President, Confederación Médica Sindical Boliviana), and Dr. Javier Pescador. To them all, and to the many others who made us the object of an unvarying kindness, goes our deeply felt gratitude.

\section{REFERENCES}

Anderson, J. Ringland (1947). “Ocular Vertical Deviations”, Brit. J. Ophthal., Monograph Supplement 12. B.M.A., London.

Belfort MATtos, R. (1958). Arch. bras. Oftal., 21, 106.

BERKE, R. N. (1947). Arch. Ophthal. (Chicago), 38, 605.

BIELSCHOWSKY, A. (1939). In A. von Graefe and T. Saemisch, "Handbuch der gesamten Augenheilkunde", 2nd ed., bd. 8, abt. 1. Springer, Berlin.

CRONe, R. A. (1954). Brit. J. Ophthal., 38, 591.

GRAB, B. (1956). J. Génét. hum., 5, 120.

JAMPOLSKY, A. (1957). Trans. Amer. Acad. Ophthal., 61, 689.

JöHR, P. (1953). J. Génét. hum., $2,247$.

SHEKTER, W. B. (1955). Amer. J. Ophthal., 39, 359.

SolARES, A. (1957). Personal communication.

Urrets-Zavalía, A., Jr. (1948a). Arch. Oftal. B. Aires, 23, 124. (1948b). Ibid., 23, 172.

(1948c). An. Soc. mex. Oftal., 22, 263.

(1950). Arch. Soc. oftal. hisp.-amer., 10, 485.

(1952). Arch. Oftal. B. Aires, $27,329$.

(1955). "XVII Conc. Ophthal."” Canada, U.S.A., 1954, Acta, vol. 1, p. 434.

(1955). Brit. J. Ophthal., 39, 11.

(1956). A.M.A. Arch. Ophthal., 55, 526.

(1960). Trans. Amer. Acad. Ophthal., in the press. 